J. R. Jaffe, J. Jamieson, P. Jenson, J. V. Jessler, E. Joffe, G. Johnson, J. C. Johnson, I M. Jones, P. A. K. Jones, W. D. Joseph, T. Joyce. A. T. Kennie.

A. Laing, L. Lamont, W. I. Lamont, M. E. Lampard, B. K. Lane, N. Laing, L. Lamont, W. I. Lamont, M. E. Lampard, B. K. Lane, H. A. Lang, C. E. Langley, F. W. Lapage, R. P. Lawrie, M. Lee,
H. N. Levitt, B. Levy, N. Levy, A. S. Liddell, D. C. Lindley, J. Lipetz, S. Lipetz, G. K. Lloyd, T. Logan, W. J. H. Lord.

S. V. McAndrew, A. McBain, G. L. McCulloch, J. MacDonald, J. McEwen, M. McEwen, W. M. Macfarlane, D. McFarlane, A. M. Macfie, J. G. McGavin, J. McGlone, I. G. McGregor, R. McIntosh, A. Mackay, R. M. Mackean, W. M. Mackean, H. M. Mackenzie, H. M. Mackey, L. MacKie, A. Mackintosh, R. E. McLachlan, R. C. A. C. MacRae, C. F. R. Mallett, H. R. Marker, T. C. K. Marr, H. F. Martin, W. J. Meldrum, N. E. Melling, A. E. H. Mence, P. Mestitz, G. H. Miles, J. R. Miles, A. C. Millar, J. R. Millar, S. Miller, W. T. Mills, D. T. Milnthorpe, M. Milnthorpe, R. R. W. Mirrey, H. J. Missen, A. Model, R. H. Morgan, N. Morison, J. E. Morrison, D. J. Morton, R. C. Morton, J. T. Mucklow, D. Murray, E. A. Murray, J. M. Murray. L. Naftalin, $M$. Niren.

M. R. Oates, M. J. O'Flaherty, R. L. Orchardson, D. B. R. Osborne, J. H. Owen.

W. H. Palmer, J. L. Pardoe, H. Parkes, J. N. M. Parry, W. M. Patterson, K. M. Pearson, D. D. Pennie, J. H. S. Perrett, R. P. Phillips, L. A. Pike, R. J. F. H. Pinsent, J. M. Pirrie, H. P. Player, H. R. Playfair, C. A. Pike, R. J. F. H. Pinsent, J. M. Pirrie, H. P. Player, H. R. Playfair, C. D. Politeyan, A. G. B. Poole, J. R. F. Popplewell, C. L. Po F. S. Rae, A. K. Ravenscroft, G. A. Readett, A. G. Reid, J. L. Rennie, J. A. Riddell, J. Roberts, A. A. Robertson, G. T. Robertson, W. M Robinson, E. J. E. Roche-Kelly, A. F. Ross, A. G. Ross, E. J. R. Rossiter, G. A. Roulston, A. D. Rowlands, A. J. Russell, G. T. Rutherford, L. C. Rutter.

J. G. Sandeman, R. H. Sandiford, L. Schreiber, J. S. Scobbie, E. Scott, E. B. Scott, I. M. Scott, J. G. Scott, R. Scott, R. H. Scott, W. T. Scott, M. K. M. Scrimgeour, G. E. Sharp, J. A. Shearer, J. T. Sherlock,
H. Sherry, W. A. Shiells, R. Simpson-White, R. G. Sinclair, J. L. Skene, D. M. Slessor, B. S. Smith, G. Smith, G. M. S. Smith, J. R. Smith, W. D. Smith, W. E. Smith, S. Smullen, K. Southgate, B. J. Sproule, J. W. Squire, F. H. Staines, C. J. H. Starey, J. S. K. Stevenson, H Stewart, J. Stewart, J. G. Stewart, R. E. Stewart, E. M. Stocks, I. H. Stewart, J. Stewart, J. G. Stewart, R. E. Stewart, E. M. Stocks, I. H. H. Swinburn, A. Swindale.

G. M. Tanner, G. W. Taylor, H. F. Taylor, I. M. Telfer, F. F Temple, J. A. C. Terry, D. A. Thomas, D. W. P. Thomas, I. S. Thomas, B. A. Thompson, P. D. Thomson, T. J. Tiplady, A. H. Torrance, L. L. Torrance, H. Tothill, L. Tully, A. M. E. Turnbull, R. M. Turner.

P. Unwin. S. Wake, J. M. Walinck, J. H. Walker, B. E. Wall, A. B. Wallace, J. S. Wallace, W. S. Wallace, J. F. C. Waterson, R. D. Watssman, M. A. Watt, M. A. Weller, P. Wellings, J. H. W. West, D. M. Wilkinson, M. A. Watt, M. A. Weller, P. Wellings, J. W. W. West, D. M. Willikinson, I. L. Wilkinson, R. Willan, W. K. Willan, G. M. Williams, J. M. Williams, J. M. A. Williams, G. M. Willoughby, A. T. Wilson, C. J. C.
Wilson, J. Wilson, J. L. Wilson, P. K. Wilson, W. M. Wilson, C. Wood, J. F. H. Wood, L. A. C. Wood, R. N. Woodsend, H. W. Wright.

\section{REFERENCES}

Benady, D. R., and Denham, J. (1963). Brit. med. F., 2, 1569.

Eimerl, T. S. (1964). 7. Coll. of G.P.s, 7, 342.

Kessel, N., and Shepherd, M. (1962). F. ment. Sci., 108, 159.

Logan, W. P. D., and Cushion, A. A. (1958). Morbidity Statistics from General Practice, Vol. 1 (General), Studies on Medical Population Subjects No. 14. H.M.S.O. London.

Parr, D. J. (1957). Brit. F. Addict., 54, 25.

Rowntree, J. A. (1957). G.R.O. Studies on Medical Population Subjects, No. 11. H.M.S.O., London

Shepherd, $M$. (1964). In press.

Taylor, Lord, and Chave, S. (1964). Mental Health and Environment. Longmans, London.

\title{
Minor Mental Illness in London: Some Aspects of a General Practice Survey*
}

\author{
MICHAEL SHEPHERD, $†$ D.M., M.R.C.P., D.P.M. ; BRIAN COOPER $\ddagger$ M.D., D.P.M. ; \\ A. C. BROWN, $\ddagger$ M.B., D.P.M. ; G. W. KALTON, $\ddagger$ M.SC.ECON.
}

Brit. med. F., 1964, 2, 1359-1363

During the past six years a small research team working at the Institute of Psychiatry§ has been engaged in studies of psychiatric morbidity as it is encountered in the field of general practice. This work has been based on two major premises : first, that the prevalence and incidence of minor psychiatric disorders in the community is on a scale altogether beyond that indicated by hospital statistics ; secondly, that the G.P. is, or ought to be, a key-figure in the nation's mental health services. It has therefore seemed logical to pay attention both to the quantitative aspects of the problem-that is, to the extent and distribution of psychiatric illness in general-practice populations-and to the question of the G.P.'s function in relation to such disorder. In this field of inquiry epidemiological and "operational" studies are closely inter-related. Earlier reports (Shepherd et al., 1959 ; Kessel, 1960 ; Cooper et al., 1962) have gone some way to confirming the magnitude of the problem and the practicability of the methods of inquiry adopted. The present paper describes some of the findings of a large-scale survey which has recently been completed.

The distribution of major psychiatric disorders in general practice is relatively easy to determine. Prevalence is low, and the task of head-counting correspondingly easy ; moreover, patients suffering from these disorders can usually be identified by the practitioner without much difficulty, either because of the distinctive clinical picture or because of their collision with one or other of the social services. By contrast, the minor neurotic reactions are common; many are closely related to physical diseases or symptoms, so that estimates of their frequency must take account of other forms of morbidity; their classification is controversial, and some, at least, of the wide variation in their reported prevalence is undoubtedly explicable in terms of the preconceptions of individual physicians. These difficulties were all prominent in the present survey, which was carried out with the co-operation of 80 G.P.s from 46 practices in Greater London. This report concentrates on four aspects of the survey, selected for their wider significance as well as for their place in the context of the investigation. They comprise (1) the selection of doctors, (2) the recording and classification of psychiatric disorders, (3) the estimated prevalence and distribution of psychiatric morbidity, and (4) the problem of interpractice variation in reported morbidity rates.

\section{Selection of Doctors}

The reported morbidity experience of a single practice, however careful the recording, is subject to the limitations imposed not only by the size and nature of the practice population but also by the pronounced variation between doctors, which precludes simple multiplication of the number participating without regard to the nature of their recruitment. The published literature suggests that there is a relatively small group of G.P.s

\footnotetext{
* An abridged version of this paper was presented to the General Practice Section of the Royal Society of Medicine, March 1964.

t Reader in Psychiatry, Institute of Psychiatry, the Maudsley Hospital, London.

$¥$ Research Assistant, Institute of Psychiatry, the Maudsley Hospital, London.

Supported by a grant from the Nuffield Foundation.
} 
who are busily engaged in reporting their practice statistics for all forms of morbidity, and about whose figures Eimerl (1960) has commented with justice: "It is probable that the composite picture presented by the relatively few practitioners taking part in epidemiological studies will not be the same as that presented if all the large numbers remaining outside the study were to be included. The validity of conclusions based on observations made by self-selected groups of observers may be questioned. Their application to the vast majority of practices not so investigated can be doubted." The potential influence of bias on reported psychiatric illness is so important that it was decided to try to obtain a random sample of G.P.s, rather than rely on volunteers. The results of this attempt are of some interest in their own right.

A random sample of one in 80 names from the London Executive Council's Medical List furnished 51 doctors from 27 practices, to all of whom we wrote and from all of whom we received replies. Over half the replies were in the negative. One doctor from each of the 27 practices was then interviewed in order to assess $(a)$ the reasons for refusal, $(b)$ the feasibility of including those doctors who were willing to collaborate, and $(c)$ the type of bias we might be introducing by having to rely on only the co-operative physicians. Twelve practices, we concluded, would be "available" for the study, and 15, for various reasons, " unavailable." The two groups could not be distinguished by age of doctor, locality of practice, or social characteristics of practice population. While size of patientload was not an important distinguishing factor, doctors in partnerships and group practices were more able and willing to co-operate than single-handed practitioners, and the possibility of co-operation was clearly related to the presence of ancillary help. Interestingly enough, at interview not one of the unavailable doctors referred to their secretarial facilities; the commonest grounds offered for non-cooperation were ill-health, impending retirement, and overwork. To the subject-matter of the inquiry the general attitude was one of tolerant indifference. Only four doctors in the available practices had been sufficiently interested in psychiatry to have attended any postgraduate lecture or course, and only three in the unavailable group were frankly antipathetic.

From these findings we concluded that an attempt to call on the services of a random sample of urban G.P.s-which to our knowledge would be the first of its kind-would not be feasible. It was decided instead to fall back on volunteers, but to secure as representative a group as possible. To this end we plotted the distribution of our available practices among the London postal districts, and then set out to supplement them by approaching G.P.s in each of the remaining districts until we had as many practices as we could hope to include in the survey. These additional practices were picked in two ways. Some were already known to us from the pilot survey or other previous research contacts ; the majority, however, were drawn from the London Executive Council list, practices in each district being approached consecutively until one proved available. This method provided a wide scatter of practices, though some parts of London were too distant to be covered, while in others we had great difficulty in finding anyone to co-operate.

Examination of some of the chief characteristics of the participating doctors and their practices showed that they were in most respects a representative group, and in particular that they did not include an excessive number of G.P.s with a special interest in psychiatry.

\section{Method : Recording and Classification}

The survey ran for 12 months from October 1961, and was preceded by a pilot study, details of which have been published elsewhere (Cooper et al., 1962). The primary aim was to collect relevant medical and social information on all consulta-

tions made by a one-in-eight sample of N.H.S. registered patients over the age of 15 during the year of observation. For the purpose a specially designed card was inserted into each of approximately 18,000 case envelopes. Of the 52 practices originally selected two withdrew during the survey and four proved unacceptable because of inadequate standards of recording. In addition there was some inflation of practice records, and the final number of patients at risk throughout the survey was just under 15,000 .

The standard classifications of psychiatric morbidity are notoriously unsatisfactory for those minor disorders which bulk so large in the G.P.'s case-load. Crombie (1963), for example, has pointed out that " ... the bias in nomenclature against emotional disease is reflected in its most extreme form in the International Classification of Disease," and has employed a fivefold subdivision of morbidity according to the relative importance of organic and emotional components. Such a view of the problem acknowledges the importance of psychological factors in forms of illness other than those which are formally recognized as " psychiatric." On this basis, and with the experience of previous studies, the following system of classification was evolved for this survey:

Formal Psychiatric Illness

1. Psychosis-schizophrenia, manic-depressive psychosis, organic psychosis.

2. Mental subnormality.

3. Dementia-deterioration of mental powers in excess of normal ageing process.

4. Neurosis-anxiety state; depressive, hysterical, phobic, or asthenic reactions; others.

5. Personality disorder.

Psychiatric-associated Conditions

6. Physical illnesses

7. Physical symptoms

8. Physical illnesses

9. Physical symptoms

10. Other psychological or social problems.

The schema makes it clear that the term "psychiatric" is used in two distinct ways: on the one hand to denote a group of conditions corresponding roughly to Section $\mathrm{V}$ of the International Classification- " mental disorder, psychoneuroses and personality disorder" (W.H.O., 1948), and on the other to characterize certain cases which may have been given an " organic" diagnosis, but where the G.P. regarded psychological factors as important in aetiology or outcome. The former group we have termed "formal psychiatric illness"; the latter "psychiatric-associated conditions," which includes the "psychosomatic" and "stress" disorders of other workers, as well as what we have called "psychological or social problems." This last subgroup comprises cases where the patient manifests transient psychological disturbance not amounting to illness, and related largely to social or interpersonal difficulties for which medical help is sought.

The logic of this system was explained to and accepted by all participating doctors, who then proceeded according to their customary clinical practice. In all cases the G.P., who alone has access to the personal and family background of his patients, was sole arbiter in the choice of appropriate categories. The prior agreement on nomenclature, however, rendered the collation of results a more meaningful procedure.

\section{Results}

Two important preliminary observations should be stressed. First, the demographic characteristics of the 15,000 patients at risk during the survey year indicated that they did not differ significantly from the population of the County of London 
(General Register Office, 1963) ; and secondly, the general standard of recording was satisfactory.

Fig. 1 demonstrates that according to the patient consulting rate for different categories of morbidity formal psychiatric illness is in the forefront of conditions presenting in general practice. For purposes of comparison the G.P.s' diagnoses have been grouped into a dozen broad categories, and it can be seen that for women psychiatric disorders rank third among presenting conditions, while for both sexes combined they rank fourth. It is of some interest to note that a comparison of our figures with those of individual diagnostic categories in the study published by the G.R.O. based on the survey of the College of General Practitioners shows that in spite of the different methods of classification the broad totals for general morbidity are very similar (Logan and Cushion, 1958).

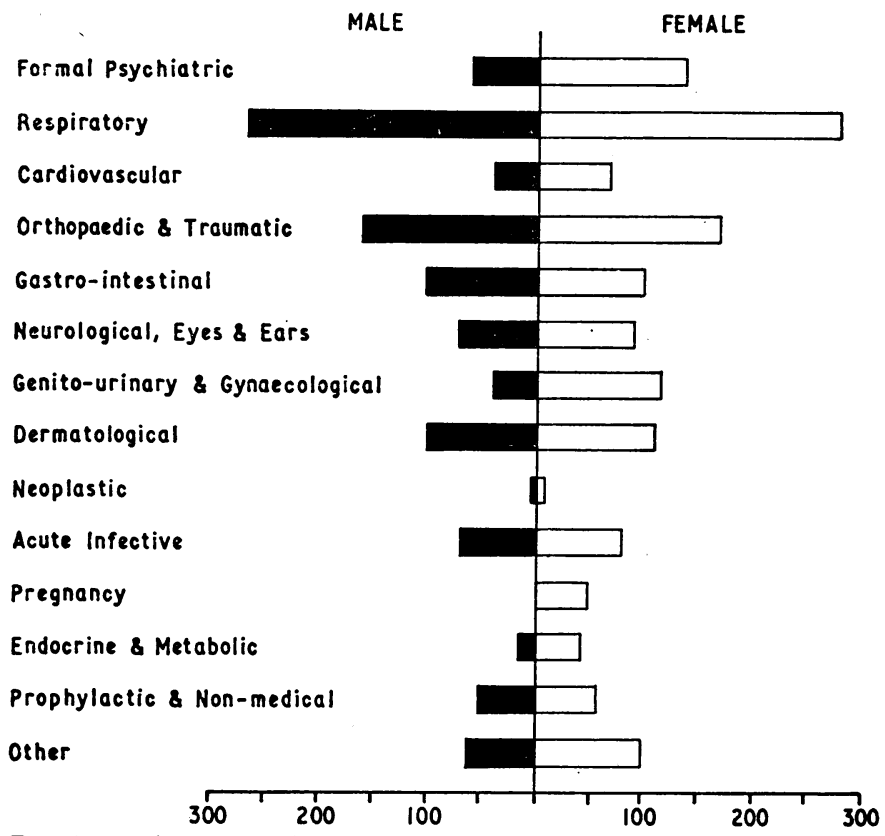

Fig. 1.-Patient consulting rate per thousand at risk, over the age of 15 , for each category of morbidity.

The rates reported for "formal psychiatric illness" take no account of "psychiatric-associated conditions." Table I, which shows total psychiatric morbidity rates by diagnostic subgroup, makes it clear that formal psychiatric illness comprises only about two-thirds of the whole; psychiatric disorder in some form was reported in approximately $14 \%$ of the population.

Table I also demonstrates how relatively uncommon are the psychoses in general practice and how close is the nexus between neurotic disorders and physical illness.

With regard to the age, sex, and marital distribution of psychiatric morbidity, we found the usual female preponderance, with a sex ratio of $1: 2$, and a peak in the middle years. Single men appear to carry a higher risk than married men between the ages of 25 and 65 , after which they have, if any-

Table I.-Patient Consulting Rates for Psychiatric Illness, Per 1,000 at Risk Over the Age of 15, by Sex and Diagnostic Group

\begin{tabular}{|c|c|c|c|c|c|c|c|}
\hline \multicolumn{5}{|l|}{. } & \multirow{2}{*}{$\begin{array}{r}\text { Male } \\
2 \cdot 6 \\
1.6 \\
1.2 \\
55.7 \\
7 \cdot 2\end{array}$} & \multirow{2}{*}{$\begin{array}{r}\text { Female } \\
8.6 \\
2.9 \\
1.6 \\
116.6 \\
4.0\end{array}$} & \multirow{2}{*}{$\begin{array}{r}\begin{array}{r}\text { Both } \\
\text { Sexes }\end{array} \\
5 \cdot 8 \\
2.3 \\
1.4 \\
88.5 \\
5.5\end{array}$} \\
\hline $\begin{array}{l}\text { Psychoses } \\
\text { Mental subnormality } \\
\text { Dementia } \\
\text { Neuroses } \\
\text { Personality disorder }\end{array}$ & $\begin{array}{l}\cdots \\
\cdots \\
\cdots\end{array}$ & $\begin{array}{l}\cdots \\
\cdots \\
\cdots\end{array}$ & $\begin{array}{l}\cdots \\
\cdots \\
\cdots\end{array}$ & $\begin{array}{l}\ldots \\
\cdots \\
\cdots\end{array}$ & & & \\
\hline \multicolumn{3}{|c|}{ All formal psychiatric illness } & . & $\ldots$ & $68 \cdot 4$ & $133 \cdot 8$ & $103 \cdot 6$ \\
\hline \multicolumn{4}{|c|}{$\begin{array}{l}\text { Psychosomatic conditions } \\
\text { Organic illness with psychiatric overlay } \\
\text { Psycho-social problems } \\
\end{array}$} & $\because$ & $\begin{array}{r}24 \cdot 5 \\
13 \cdot 1 \\
4 \cdot 6\end{array}$ & $\begin{array}{l}34 \cdot 5 \\
16 \cdot 5 \\
10 \cdot 0\end{array}$ & $\begin{array}{r}29 \cdot 9 \\
15 \cdot 0 \\
7 \cdot 5\end{array}$ \\
\hline \multicolumn{4}{|c|}{ All psychiatric associated conditions .. } & . & $42 \cdot 2$ & $61 \cdot 0$ & $52 \cdot 3$ \\
\hline \multicolumn{2}{|c|}{ Total psychiatric morbidity } & $\cdots$ & . & . & $97 \cdot 6$ & $175 \cdot 5$ & $139 \cdot 6$ \\
\hline
\end{tabular}

thing, a lower risk. For women the pattern is rather different ; married women tend to have higher rates than single, and this is most apparent in age-group 25-44. Young widows are particularly vulnerable; over half the widows between 25 and 45 had a psychiatric condition diagnosed during the survey year.

Fig. 2 makes it clear that the prevalence of psychiatric disorder in general practice, unlike that revealed by hospital statistics, is greatest in the middle years of life. The significance

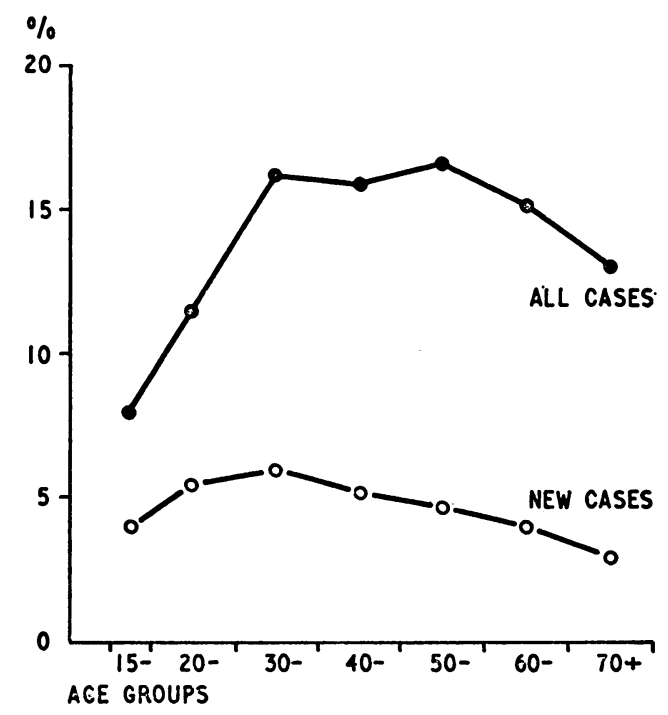

FIG. 2.-Patient consulting rate for psychiatric morbidity by age group. New cases and all cases-men and women combined.

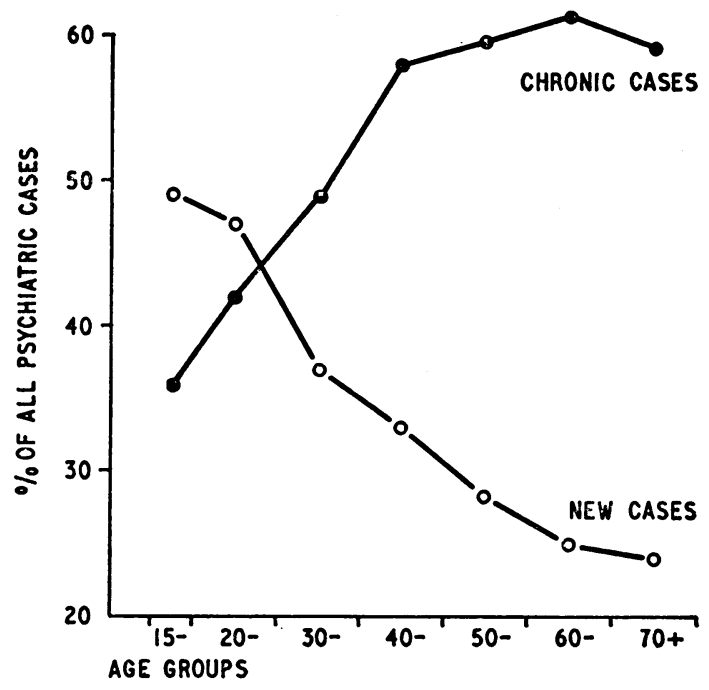

FIG. 3.-New psychiatric cases and chronic psychiatric cases as a percentage of all psychiatric cases-men and women combined.

of Fig. 2 is increased by our ability to include an estimate of the number of "new" cases, defined as patients who had not presented with psychiatric symptoms during the preceding year. The shape of the age-curve for new illness compared with that for all psychiatric illness suggests an accumulation of chronic cases in the higher age-groups. We were able to confirm this inference from the G.P.s' direct enumeration of chronic cases, defined as those with symptoms continuously present for at least one year at first consultation during the survey period. In Fig. 3 the distribution by age-group of these chronic cases is superimposed on that of new cases to demonstrate that chronic psychiatric disorder accumulates in the older sections of the population. Evidently, neurotic illness must take its place among the more important causes of chronic sickness. 
Further analysis also showed a strongly marked association between psychiatric disorder and chronic organic illness $(r=$ +0.39 ).

\section{Interpractice Variation}

These global findings, derived from the pooled statistics of all the survey practices, must be viewed in the context of a wide variation in individual practice rates. The distribution is shown in Table II. A ninefold difference separates the highest from the lowest reporters, and the overall variation is highly significant $\left(\chi^{2}=421.0\right.$; d.f. $\left.=45 ; \mathrm{P}<0.01\right)$. Only about $8 \%$ of the total variance could be accounted for by the fluctuation associated with random sampling. The remaining $92 \%$ of "non-random" variance can be ascribed to several possible causes, each of which is briefly considered in turn.

TABLB II.-Interpractice Variation (1). Psychiatric Morbidity. Rates
Per 1,000 at Risk Over the Age of 15, by Practice

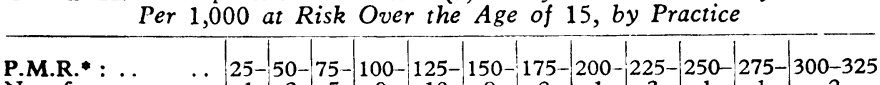

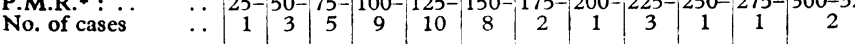

- Psychiatric morbidity rate.

The simplest explanation is that the doctors who were the poorest recorders reported fewest cases. If this were so there should be a positive correlation of practice rates for psychiatric illness with the total patient consulting rates-that is, the proportion of the practice sample with recorded consultations during the year. In fact, there was virtually no correlation ( $\mathbf{r}=-0.01$ ), which suggests strongly that discrepancies in recording could not have played an important part in producing the reported variation.

The differences might also reflect the social and demographic characteristics of the practice populations. Ecological studies have shown that differences in the socio-cultural milieu can exercise an important influence on the rates reported for the

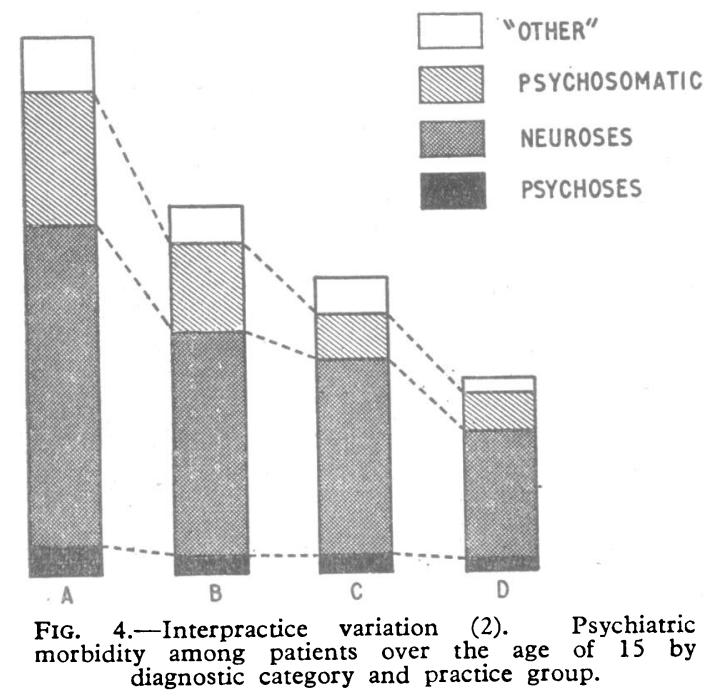

major psychiatric illnesses. Similar factors, as well as the effect of selective recruitment of patients by individual doctors with special interests and experience, might be expected to be at least as important in affecting the prevalence of minor disorders. With the relatively crude data available it was not feasible to evaluate the complex ecological forces which may have been operating in the survey practices. It was, however, possible to analyse the findings in terms of the age, sex, and social-class distribution of the practice populations and, in addition, of the "patient mobility"-that is, the relative amount of patient-turnover in each practice-which provides a rough index of the geographic mobility in each practice area. These factors-age, sex, social class, and mobility combined-were estimated by the technique of multiple regression analysis to account for $37 \%$ of the "non-random" variance in reported psychiatric illness rates.

These computations take no account of the varied diagnostic habits and opinions of individual practitioners. Some indirect evidence of the importance of the latter was provided by the finding that interpractice variation was greatest for " psychiatric-associated conditions," rather less for the neuroses, and barely significant for the psychoses. The reported differences, therefore, were least for the most readily identified forms of psychiatric disorder and greatest for those where medical opinion is most divided. The relevant data are displayed diagrammatically in Fig. 4, where the survey practices have been combined in four groups according to their psychiatric morbidity rates.

In previous psychiatric surveys it has been insufficiently stressed that the doctor is, in effect, an uncalibrated recordinginstrument, and the factors determining his mental set when confronted with a case of psychiatric disorder are still largely unexplored. We have made an attempt to evaluate them by constructing a questionary which covers not only such factual information as the doctor's age, number of years qualified, and size of patient list, but also his attitudes towards a number of interrelated topics, including the management of neurotic patients, the value of psychiatry as a specialty, and the importance of psychogenic factors in physical illness (Cooper, 1964). By scoring the responses of 75 of the G.P.s to this questionary we have derived several indices related to what may be described as their " psychiatric orientation." Statistical analysis showed that while the G.P.'s age, his postgraduate training, the size of his list, and the number of patients he saw during the survey year did not correlate significantly with his reported rate for psychiatric consultations, his attitude scores did (the highest coefficient being +0.44$)$. We therefore repeated the multiple regression analysis, this time including the doctor's attitude scores as extra variables; in the case of group practices weighted mean attitude scores were used. By this method we were able to increase the proportion of the "non-random" variance accounted for from $37 \%$ to $55 \%$.

The rest of the variance could not be analysed with the information at our disposal. Clearly, the more subtle aspects of the practitioners' attitudes and habits could not have been tapped by our relatively blunt instruments of inquiry. Perhaps more important, there was some independent evidence of real differences in the illness-experience of practice populations. The Cornell Medical Index Health Questionnaire (Culpan et al., 1960 ; Brown and Fry, 1962) was administered to a sample of surgery attenders in 14 of the practices, and $\frac{9}{2}$ responses indicated a marked variation between patient- $\mathrm{N}$ populations, at least in respect of self-recorded morbidity. Moreover, there was significant variation in the reported rates for most of the categories of physical illness employed in the survey. The prevalence of chronic organic disease, as has $\mathrm{N}$ been noted, was positively correlated with that of psychiatric $\omega$ illness, so that the level of all chronic ill-health would appear to vary between practices. Since the personal characteristics 0 of the practitioner may play some part in determining the $\mathbb{D}$ area and the type of practice in which he settles, it is clear that? reported practice morbidity rates may be the product of a ${ }^{T}$ complex interaction between doctor and patient-population.

\section{Conclusions}

The significance of large-scale surveys of psychiatric mor-응 bidity in general practice is illustrated by the findings of this study. They confirm the existence of vulnerable subgroups in the population suffering from minor disorders which are inadequately represented in hospital practice. By so doing they provide essential information both for public-health planning 
and for the detection of causal associations among these complex conditions.

At the same time the study underlines the need to extend and refine available techniques of measurement. Even with carefully defined criteria of illness the wide variation between practitioners' prevalence rates points to two potent groups of factors. The first of these relates to the ecological differences between practices and can be offset by paying regard to the size and representativeness of the sample of participating doctors. The second relates to the doctor, his attitudes, and his interactions with his patients; for psychiatric illness, as we have shown, they constitute a major source of variation.

\section{Summary}

This paper reports on a general practice survey of psychiatric morbidity carried out in the Greater London area. The sickness experience of nearly 15,000 patients on the lists of 80 practitioners was studied over a period of one year. It was shown that minor psychiatric disorders, classified according to a predetermined schema, were diagnosed in $14 \%$ of the population at risk. Neurotic illness was most prevalent among middle-aged females and proved to be an important cause of chronic illness. The reasons for interpractice variation in recorded morbidity are discussed.

We are grateful to the following general practitioners, whose cooperation made this study possible.

D. Adderley, G. J. Arendt, J. B. Armstrong, June Armstrong.
D. Berry, D. Billig, A. Blofeld, E. Bronson, H. Brostoff.
R. Clipstein, J. H. Clough, J. Cohen, N. Cohen.

J. Dillane.

G. M. Edmonds, H. H. A. Elder.

G. M. Edmonds, H. H. A. Elder.

Fletcher, K. B. Foster, P. Frazer, P. Freeman, J. Fry, L. Fry.

R. Grahame, D. Grant.

S. P. Halpin, J. C. Hardy, H. Hart, J. Hewetson, E. H. Hiley, P. Hopkins, J. Horder, G. Horton, K. . Huntington.

H. Jeffs, C. Josephs.

M. A. Kalina, C. O. Kennedy, D. L. Kerr, C. D. Korn, R. Korn.

S. Lee, B. A. Lees, H. N. Levitt, F. Lucas.

W. T. MacDonald, J. McEwan, T. Madden, D. H. Mellins, S. Mellins,

P. Morris, W. B. Mumford.

R. H. V. Ollendorff.

L. T. Page, D. Perkins, J. Powell-Evans.

J. N. Rea, F. Ross, E. M. Rosser, S. S. Rowell, A. Ryle.

I. J. Sachs, K. Sanders, J. Sayers, K. Scott, M. Scott, J. E. Scriven, E. Seifert, M. Smith, H. Snowden, A. Spier, R. Stowe. M. Thorpe, E. D. Tod.

J. Vance. Wall, T. H. Warburton, J. W. Wigg, R. Wigoder.

REFERENCES

Brown, A. C., and Fry, J. (1962). 7. psychosom. Res., 6, 185.

Cooper, B. (1964). De Medicina tuenda, 1, 43.

Brown, A. C., and Kalton, G. (1962). 尹. Coll. gen. Practit., 5, 590. Crombie, D. L. (1963). Lancet, 1, 1205.

Culpan, R. H., Davies, B. M., and Oppenheim, A. N. (1960). Brit. med. F., 1, 855 .

Eimeri, T. S. (1960). 7. Coll. gen. Practit., 3, 246.

County Report, London. H.M.S.O., London.
Kessel, W..I. N. (1960). Brit. F. prev. soc. Med., 14, 16.

Logan, W. P. D., and Cushion, A. A. (1958). Studies on Medical and Population Subjects, No. 14. H.M.S.O., London.

Shepherd, M., Fisher, M., Stein, L., and Kessel, W. I. N. (1959). Proc. roy. Soc. Med., 52, 269.

W.H.O. (1948). International Statistical Classification of Diseases, Injuries, and Causes of Death. Geneva.

\title{
Haemodynamic Effects of Carotid Artery Stenosis
}

\author{
J. G. BRICE,* M.B., F.R.C.S. ; D. J. DOWSETT, $\dagger$ B.SC. ; R. D. LOWE, $\ddagger$ M.D., M.R.C.P.
}

Brit. med. F., 1964, 2, 1363-1366

Though atherosclerosis of carotid and vertebral arteries is common its significance is debatable. Hutchinson and Yates $(1957,1961)$ found a high incidence in a post-mortem series of patients who had had a cerebrovascular accident, but they did not study any control subjects; they suggested that extracranial arterial disease was a common cause of cerebral infarction through its direct effect on cerebral blood flow. Schwartz and Mitchell (1961) showed that atherosclerosis of these arteries, as with atherosclerosis elsewhere, correlated well with age, that it was common even in patients without cerebrovascular accidents, and that a correlation between cerebral infarction and extracranial atherosclerosis could be due largely to the fact that both were correlated with age.

The occlusive lesions described by these authors varied from small plaques scarcely narrowing the arterial lumen to complete occlusion of one or more of the extracranial arteries. The incomplete lesions were classified, according to the percentage reduction of the normal lumen, into mild or moderate (less than $50 \%$ reduction) or severe (more than $50 \%$ reduction); no evidence is available to assess the possible effects of such stenosis on cerebral blood flow.

Alteration of calibre may be of importance either directly, by its effect on cerebrovascular resistance, or indirectly, producing turbulent conditions of flow which might predispose to local platelet aggregation. In this paper we are concerned with the effect of narrowing of carotid arteries on their hydraulic resistance only, and report experiments designed to determine the approximate dimensions and hydraulic resistance of the minimum narrowing which has a detectable effect on blood flow through the artery. We have measured pressure gradient and flow in the human carotid artery and defined a degree of constriction which has just detectable haemodynamic effects ; in order to assess the influence of shape and length we have then reproduced this constriction in vitro in a perfusion circuit and matched its hydraulic resistance with that of artificial resistances. Some of these results have already been briefly reported (Brice, Dowsett, and Lowe, 1964).

\section{Methods}

Apparatus.-Carotid artery flow was measured by a gated sine-wave electromagnetic flowmeter (Medicon FM6) using an external probe. Pressure was measured at two points about $5 \mathrm{~cm}$. apart, using 22-gauge needles inserted into the carotid artery and connected by $80 \mathrm{~cm}$. of nylon tube (No. 2 nylon,

\footnotetext{
* Research Assistant, Neurosurgical Department and Medical Unit, St. George's Hospital, London.

† Research Assistant, Neurosurgical Department and Medical Unit, St. George's Hospital, London. Wellcome Senior Research Fellow, Neurosurgical Department and
Medical Unit, St. George's Hospital, London.
} 